\title{
Ni trata ni contrato. Lectura de Cant 8, 8-10 desde los ojos del Amor que libera
}

\author{
Neither trade nor contract. \\ Reading of Cant 8, 8-10 from the eyes of love that sets free
}

\begin{abstract}
Resumen
Este artículo pretende explorar algunos aspectos del libro de Cantar de los Cantares que son indispensables para una hermenéutica liberadora en clave de género. Para ese abordaje, emprenderá el análisis específicamente del capítulo 8, 8-10 y analizando este texto pondrá énfasis en los elementos lingüísticos y gramaticales del pasaje. Revisará lo que otros abordajes han dicho a propósito de esta porción en sí, y así, dialogará críticamente con esos nichos de sentido que han ido configurando una mirada utilitarista y prejuiciada sobre la sexualidad, el matrimonio, el amor y los cuerpos de las mujeres. Denunciará con ello la existencia de posicionamientos y actitudes que aún coexisten hoy en día y devienen en prácticas naturalizadas de violencia e inequidad, sobre todo respecto a la mujer. Trata, tratos, contratos, afectan a la familia humana que somos en nuestras libertades y derechos. Se anunciará también que, a través de ella, la mujer que cuenta todo en este texto, se percibe la esperanza en un mundo mejor posible a través de una manera diferente y posible de mirar y leer.
\end{abstract}

Palabras clave: Mujer, Inequidad, Sexualidad, Familia, Perspectiva de género

\begin{abstract}
:
This article aims to explore some of the aspects of the biblical book The Song of Songs, which are instrumental in developing liberating hermeneutics from a gender perspective. In order to achieve that goal, an analysis of Chapter eight, verses 8 to 10, will be carried out. This passage will be revisited through the examination of lexical and grammatical items. Also, other approaches to this passage will be assessed to engage in a critical dialogue with those meanings that have crystalized over time and that have shaped a utilitarian and prejudiced attitude towards sexuality, marriage, love, and the feminine body. Hence this article will denounce the ongoing presence of cer-
\end{abstract}

\footnotetext{
${ }^{1}$ Biblista; Pastora de la Fraternidad de Iglesias Bautistas de Cuba (FIBAC); Profesora del Seminario Evangélico de Teología de Matanzas (SET) y el Instituto Superior Ecuménico de Ciencias de la Religión de la Habana (ISECRE); Especialista en el área de Articulación Ecuménica, Fe y Sociedad del Centro Oscar Arnulfo Romero de Cuba (OAR), (Correo electrónico: drufinpardo@gmail.com).
} 
tain attitudes and positions coexisting to date which become accepted practices of violence and inequity, especially against women. Trafficking, treatments, contracts are all phenomena that affect the human family we are, our rights and liberties. It will also be announced that through her, the woman who tells everything in this text, hope in a better possible world is perceived through a different and possible way of looking and reading.

Key words: Women, Inequity, Sexuality, Family, Gender perspective

Los cuerpos cambian y esa mujer lo sabe. Desde pequeña le anunciaron que un día le sucedería, sangre por medio y con dolores; y que a partir de ahí comenzaría un conteo regresivo. Su corazón empezó a acompasarse sin quererlo al tic-tac de esa bomba de tiempo que desde antaño se empeña en recordarle: ¡queda menos...cada vez menos! Menos para lograr un buen matrimonio antes que se marchite la belleza. Menos para quedar embarazada antes que empiecen a vencerse - hasta morir- los óvulos. Menos para lograr que su familia, a través de ella, llegue a ser algo más. Y así, de a poco, menos es la palabra con que termina por quererse menos. Tic... tac... como el reloj de Nunca Jamás le acecha y le persigue el miedo a naufragar, a desmembrarse, la fobia a ser marcada por la vida, a perder o perderse, a ostentar cicatrices. Tic...tac... A toda hora. No hay descanso. ¡El reloj nunca para! Todos se lo re-cuerdan. Este miedo amenaza con devorar por dentro su pedazo de infancia, su inocencia, lo lúdico, el deseo, las ganas de volar, pero ¿lo logra?

\section{El Amor es un canto sin tiempo y sin nombre...}

El libro del Cantar de los Cantares hace parte de los Ketubim o Escritos, que es a su vez la tercera sección de la Biblia Hebrea. Es el primer libro de los Megillot o "Cinco rollos" de esa colección que, según se sabe, eran y son leídos en diversas fiestas judías. Cantares es una lectura de la fiesta de la Pascua. Liberación, recreación, renacimiento, nueva vida: el Amor trae en sí todo eso ¡no habría para estos cánticos mejor momento ni lugar!

Su título en hebreo, "El Cantar de los Cantares", es un superlativo que significa la mejor o la más excelsa de las canciones, el cantar por excelencia. La biblia hebrea así lo nombra y lo ubica después de Job. La LXX lo titula Asma Asmaton y lo coloca después de Eclesiastés, entre los Sapienciales. La Vulgata lo llama Canticum Canticorum, o sea, el Canto de los Cantos. También puede traducirse como el mejor cantar o el más bello cantar y, como acota Schöekel, el título atribuye además este canto a Salomón tomando como apoyatura la nota de 1R 5, 12 (Schöekel, 1969).

Todo parece indicar que Cantares entró al canon de la Biblia Hebrea de manera bastante tardía. Todavía en el año 90 d.C. los rabinos estaban debatiendo si habría para este libro algún lugar, sin embargo, si seguimos la 
pista a este proceso de ser legitimado como libro "en regla", parece ser que el Eclesiástico reconocía ya su existencia alrededor del año 180 d.C, Esto se puede ver cuando menciona los tres libros atribuidos a Salomón al decir "de tus cantos $(C t)$, tus sentencias $(Q o)$, tus proverbios $(P r)[\ldots]$ se admiraron las naciones $(\text { Si } 47,17)^{2}$.

De igual forma ha llegado a conocerse que para el siglo I el libro de Cantares se hallaba ya en la biblioteca de Qumrán traducido al griego, que desde el siglo I d.C. el rabinismo citaba como autoridad y que a finales de ese propio siglo I, Flavio Josefo lo incluía entre los 22 libros de su canon. También fue usado alrededor de ese mismo período en un apócrifo pues 4Esd 5,24 hace referencia a un número de 24 libros como correspondientes al canon, en cuya cuenta Cantar de los Cantares estaría ya incluido. La asamblea judía de Yavneh, finalmente, reconoce su ubicación canónica entre los años 80 y 117 (Luzarraga, 2005).

En resumen, Jesús Luzarraga dice,

se puede concluir que, aunque no se puede fijar exactamente cuándo el Ct entró en el canon, pues el mismo concepto de canon era fluctuante, para el final del siglo I a.C. el Ct estaba ya en el canon fariseo; y ciertamente para el 65 d.C. aparece reconocido como canónico por el judaísmo. Incluso se ha hipotetizado que la lista rabínica del Canon, donde está el Ct, se habría fijado ya para la época macabea (Luzarraga, 2005, p.36).

Difícil de ubicar, como lo puede ser el Amor mismo, lo cierto es que este libro deba quizás a Salomón -reconocido especialista en cuestiones amorosas (1Re 11,1-3)- el haber sido incluido finalmente en el canon bíblico. Sin embargo, teniendo en cuenta el lenguaje, el estilo, la presencia de múltiples palabras y expresiones en arameo, así como la aparición de una palabra persa $(4,13)$ y una palabra griega $(3,9)$ en su cuerpo textual; es muy poco probable que el libro en realidad proceda de autoría salomónica total o incluso parcialmente, como también y a través de los años se ha llegado a pensar.

Por otro lado, aunque aún resulta difícil localizar la data de este libro, prevalecen hasta hoy casi con igual fuerza opiniones eruditas que al asociar a Cantares con antiguas ceremonias cultuales, sitúan su fecha original de composición durante el período cananita, antes de la llegada de los patriarcas a Egipto, o sea, entre los siglos II y III a.C. Otras posturas encuentran también cierto consenso en asignarle una fecha postexílica, posterior al destierro (siglos V o IV a.C.). Ambas posturas priman en medio de otros criterios como el de su autoría salomónica que, de ser cierta, lo ubicaría sobre el siglo $\mathrm{X}$ a.C.

2 Todas las referencias bíblicas textuales serán tomadas de la versión Nueva Biblia de Jerusalén (NJB), a menos que se indique lo contrario. 


\section{El Amor toma formas caprichosas, y así también sus cantos}

Los cantos de Cantares han sido objeto de diferentes hipótesis en el afán de describirlos a través de los tiempos. Han sido considerados como una obra poética completa y también como una colección de cánticos separados. Por la propia dinámica coral de diálogos, preguntas y respuestas llegó a identificarse como un drama, pero lo cierto es que no es posible evidenciar en este libro el desarrollo de una trama dramática homogénea o coherente de forma general.

No han sido pocas las personas estudiosas de Cantares que han visto paralelos entre los cantos de este libro y los que son entonados tradicionalmente en las ceremonias de bodas orientales en Siria, por ejemplo; sugiriendo que el libro podría de hecho contener una colección de canciones derivadas de ceremonias similares en el antiguo Israel.

De igual forma, otra vertiente de pensamiento apunta a los rituales cúlticos de fertilidad como un lugar indispensable para comprender esa poesía amorosa erotizada que contiene el Cantar de los Cantares, pero -tal como acotan específicamente Pablo A. Deiros y Bernardo Stamateas- si fuera ese el caso el libro sería una colección de poemas litúrgicos, y es difícil pensar que tales expresiones litúrgicas paganas hayan sido aceptadas e incorporadas en el canon hebreo (Varios, 1995).

Todas estas miradas, sin embargo, permiten que veamos que en realidad el texto de Cantares ha transitado una larga historia antes de llegar a ser de la forma en que podemos apreciarlo ahora, $y$ bien puede tratarse originalmente de un poema primitivo que ha sido víctima de sucesivas intervenciones editoriales a lo largo del tiempo. Posicionarnos desde esta última hipótesis volvería menos conflictivo el asunto de la inclusión salomónica en el cuerpo textual del libro, ya que podría entenderse que el mismo podría haber tenido origen en el período de Salomón, siendo preservado y actualizado luego durante la época de la monarquía dividida tal como ocurrió con el libro de Proverbios y otros Escritos.

De igual forma pensarlo como una especie de canto ampliado y evolucionado por el tiempo, ayudaría a comprender la diversidad de expresiones y vocablos- algunos de los antes mencionados y otros- que devienen del análisis lingüístico y resultan a veces a veces difíciles de ubicar en un contexto histórico, y dificultan el ubicar al libro también. Serviría, por último, esta hipótesis para corroborar la filiación como lectores a una división del texto que no predica la total correspondencia homogénea entre sus cánticos, pero tampoco impide eclipsar la visión de cierta interdependencia y relación entre los poemas.

A propósito de ello y muy acertadamente, Milton Schwantes recuerda que con Cantares lo que tenemos son cánticos de amor, una especie de cancionero de la pasión donde lo que se cantaba se fue juntando y reuniendo poco a poco. Un conjunto de cantos que, de tanto usarse y cantarse, fue 
organizándose, adaptándose y conformándose hasta que devino en un conjunto de poemas que quedaría dividido como sigue (Pardo, 2004):

- Introducción: 1:1-4

- $\quad$ Primer poema: 1,5 al 2,7

- $\quad$ Segundo poema: 2,8 al 3,5

- $\quad$ Tercer poema: 3,6 al 5,8

- $\quad$ Cuarto poema: 5,9 al 8,4

- Quinto poema: 8,5-12

- $\quad$ Conclusión: 8,13-14

\section{Canto de Dios: el canto de un deseo de mujer que no se deja atrapar}

La porción de Cantares que vamos a explorar (8,8-10) se encuentra en el espacio del último poema del libro. Otras divisiones lo ubican en el espacio conclusivo, pues es amplio el consenso en identificar el verso 8,7 como el verso final, aunque no todas las personas que han estudiado el libro interpreten de igual manera el propósito de estos otros versos que siguen.

Schöekel acota que 8,6-7 puede considerarse tanto un clímax como una conclusión (Schöekel, 1969); Anne Maria Potellier, sin embargo, identifica estos seis nuevos versículos como "enigmas", criticando que algunos comentaristas prescindan de ellos amparándose, precisamente, en el criterio de que el libro termina en el versículo 8,7 y enfatiza que, amén de esto, no debe perderse de vista que estas últimas palabras enlazan expresamente con lo ya leído en el Cantar (Pelletier, 1995). Milton Schwantes, para ayudarnos a entender esta interrelación, llamó a estos versos "vasos" (vv. 5-7, vv. 8-10, vv. 11-12, vv. 13-14) y nos invitó a ver qué tipo de "bebida" en el convite del amor cada uno de estos tenía para dar (Pardo, 2004).

Lo cierto es que el mensaje y postura de cada uno de estos versículos tiene que ver con el del otro, a la vez que también es muy particular. Dado todo esto ha de ser un criterio de interdependencia el que nos sirva para explorarlos, comprender su mensaje específico dentro del propio contexto general del libro, y traerlo al ahora de nuestras realidades preguntándonos qué mensaje nos brinda sobre algún asunto en particular.

Observemos, entonces, Cantar 8,8-10.

¿Qué trae para decirnos este "vaso" en la fiesta del libro de Cantares? ¿Qué mirada sobre el amor y lo que en nombre del amor se hace nos deja vislumbrar?

\section{Cantar 8, 8:}

El verso 8 nos sitúa en un contexto temático específico de infancia y

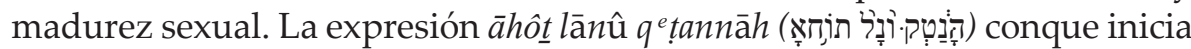
este verso lo clarifica, es una hermana (āhôt) pequeña; aún insignificante ( $q^{e}$ tannāh $h$ que literalmente es y existe (lān $\left.\hat{u}\right)$ para sus hermanas y hermanos. 
Nótese que en lān $\hat{u}$, la preposición lā (a, para) está unida al sufijo pronominal $n \hat{u}$, que corresponde en el hebreo a la primera persona común plural. Aunque el contexto general invita a traducirlo con un fuerte sentido masculino, más allá de ello, la idea de posesión familiar queda reflejada en el análisis de esta expresión particular.

La frase que abre el verso, sin duda alguna sustenta el análisis ya extendido sobre la situación en que se encuentra la muchacha: una donde para el contexto familiar impone peso de tributo que infiere el ser mujer en esa época. Esta hermanita "... sin pechos todavía” (v.8a) no ha llegado aún a su etapa de madurez sexual y la interrogante que asalta a los implícitos hermanos es qué podrán hacer concretamente respecto a ella cuando sea pedida en matrimonio, "el día que se hable de ella" (v. $8 \mathrm{~b})^{3}$ o sea, cuando notablemente empiece a ser atractiva y estar visiblemente lista para emparejar.

Algunos comentarios sobre este verso y lo que en él ocurre identifican que el hecho de que se defina a la hermana como «pequeña» no hace alusión a una infancia real, sino que constituye una metáfora de juventud como la empleada en Génesis 9,24; 27,15 y Jue 15,2. Asimismo, se alude a que entraña también una connotación cariñosa de tipo erótico como el de la "ovejita" en 2 Sm 12,3.

Por el uso rabínico del término aplicado a la "mujer núbil" que oscila entre los 12 y 14 años, hay también la tendencia a interpretar que la expresión puede tratarse de un juego - casi con visos de cortejo - donde el dodí (representado en este plural común) provoca a la muchacha casamentera,

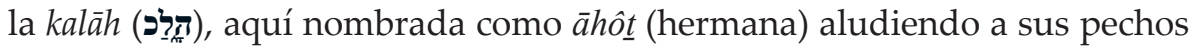
no suficientemente crecidos como si esta fuera incapaz de maternidad y de la relación sexual; a la vez que diciéndole en línea con la imaginería oriental que sus pechos así, aún pequeños, son señal de belleza juvenil y muestra de una virginidad que provoca el deseo erótico (Luzarraga, 2005).

Otros estudios como el de Milton Schwantes, sin embargo, se preocupaban por llamar la atención sobre algo también obvio: esta manera de referirse a la mujer (sea āhốt o kalāh) no es delicada, ni rebuscada. No juega sutilmente con las palabras. Por el contrario, alude crudamente a que el valor se mide por su cuerpo, por sus senos, y llama a todo, sin afeites, por su debido nombre (Pardo, 2004).

Entonces se abre espacio la pregunta ¿son modos de cortejo los que se ven en este verso 8 , o realmente se trata de algo más?

\section{Cantar 8,9:}

Tanto el predecesor verso 8 como este verso 9, muestran una preocupación muy acentuada por esta hermana aparentemente aún menor de edad, y esta preocupación no es retórica romántica, sino que apunta a ser de cariz sexual transaccional.

\footnotetext{
${ }^{3}$ La Biblia de las Américas lo traduce como "el día en que sea pedida" (v.8b, LBA).
} 
Si el verso 8 evidenció cuál era el "cuerpo" del problema y levantó la interrogante sobre qué hacer con el mismo en un momento que, al parecer, se infiere para ellos (la familia) como cada vez menos lejos; el versículo 9 intenta responder sobre esto. Y es la voz en plural, voz de familia patriarcal la que, otra vez, se hace escuchar.

El lenguaje de este versículo 9 prefiere los vocablos que hacen referencia directa al poder material, monárquico y militar. La palabra $k \bar{a} \cdot s e \bar{p}$ (פָָּ es un vocablo que significa plata, pero también dinero. Los vocablos

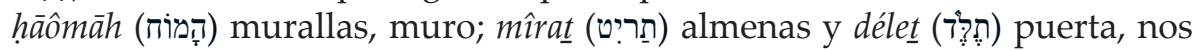
ubican en un ambiente de asedio, de conquista, de defensa. Así también los

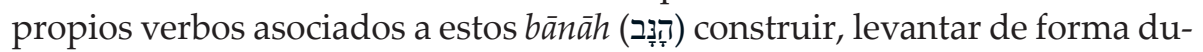
radera y lujosa, establecer materialmente, afianzar y șûr (רוּ (רוּ ) atar, asegurar, nos sitúan en una escena similar.

Algunas interpretaciones bastante extendidas sobre el pasaje proclaman que este verso 9 habla de un tiempo de preparación para el matrimonio y que la estrategia de preparación para el mismo está determinada por el carácter de ella, de modo que "la muralla sugiere la firmeza de su carácter, que será fortificado mediante torreones de plata. Así, si ella es solicitada por los jóvenes, su familia la animará y estimulará a mantener su posición virtuosa [...] si ella es puerta, es decir, está abierta a ser seducida o es accesible a ello, su familia proveerá de paneles de cedro para protegerla" (Varios, 1995).

Esta interpretación no contradice el carácter transaccional del texto, pero tampoco lo aborda críticamente, y la visión que desestime el peso de lo que el propio verso, el pasaje y el libro respecto a la mujer en sí contienen, resultará incompleta en tanto eclipse la realidad de violencia de estas prácticas y naturalice con su silencio estas brechas de inequidad, propias de aquel contexto vital.

El describir la dinámica de estezComo bien expresaba Milton Schwantes, es precisamente el matrimonio lo que constituye un problema en este fragmento y en el libro de Cantares en general (Pardo, 2004).

Además de ello, ¡el versículo habla por sí solo! No cabe duda: el amor de estos versos es amor en contienda, que se entiende en el medio de la ganancia y el lucro y hace parte de ellas. La mirada plural de "los hermanos" así lo enmarca, así lo muestra.

El sí condicional deja saber que están considerando las opciones, las posibilidades sobre la hermanita. La pregunta central en este caso radica en si el sí de ella como mujer a esta estrategia de inversión lucrativa, les será dado como ellos esperan, de forma incondicional.

\section{Cantar 8,10:}

Este verso con el que cierra el fragmento es hermoso y es un verso de mujer. Acá levanta ella la voz y da respuesta. La traducción supone un diá- 
logo en términos de ironía y desafío en el original, pues es a los hermanos a quien les corresponde velar por la hermanita (Schöekel, 1969 p. 83) y ella:

- Primero deja saber de su madurez, autocuidado y suficiencia cuando dice: "Yo soy una muralla..." (v. 10a)

- Seguidamente, a la mirada sexual, superficial y utilitaria sobre el tamaño de sus pechos contrapone una mirada donde invita a ser vista de modo diferente al declarar: "...mis pechos como torres" (v.10b) Otras traducciones enfatizan son como torres (R95) o son dos torreones (RVA)

Las metáforas mencionadas en el verso 9 expresan a una vez, como ya vimos, el deseo de los hermanos de proteger a su hermana por creerla pequeña y de embellecerla haciéndola más deseable. Aquí la novia afirma, mientras tanto, que ya ha madurado y ha encontrado la integridad, la paz, con el amado. Y así, con la palabra shalôm resuelve el diálogo conflictivo con la familia (Schaefer, 2006). La palabra shalôm, más que mera palabra es un concepto que en el contexto de este verso- y este fragmento- se reviste de un peso teológico muy fuerte dentro del contexto particular del pasaje y el del libro en general.

Ante un contexto social y familiar que es violento respecto a las mujeres, esta de nuestro canto entiende el amor como acto que podrá pacificar. En medio de una época que denigra a las mujeres jóvenes con prácticas naturalizadas de tratos y contratos, ella cree en la posibilidad de que vivir en el amor conlleva a la integridad.

Ella sale de lo pequeño donde los demás la han enmarcado. Se crece y se desmarca. Pero para entender que esta apreciación que hace sobre ella misma no es abstracta, ni constituye un simple deseo que su ser proyecta, es preciso observar cómo prosigue el texto.

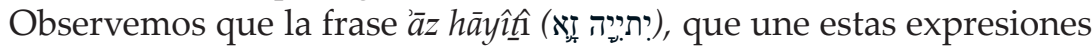

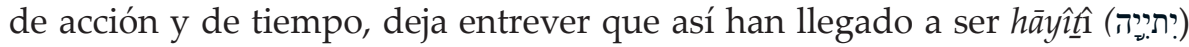
ella y sus senos al momento, en el momento $\bar{a} z$ (j) en que ante sus ojos (los ojos de quien ama) encuentra completitud, armonía y paz (shālom). La Paz en este caso - acota Schwantes- equivale a bienestar, vida buena, tranquila, apacible y plena e incluye la relación sexual (Pardo, 2004).

Es bien interesante lo que el final del verso nos sugiere. Siguiendo la imagen que dibujan sus palabras cuidadosamente llegamos a ver que lo que dice es también, como anteriormente una descripción más real y concreta que romántica abstracta. Una alusión visible y bien carnal.

Cuando de amor se trata, sabemos que el corazón late más fuerte en frente de quien se ama. La respiración se agita y el pecho entonces se levanta, se dilata, aumenta en cada inspiración. Así crecen, se yerguen sus pechos como torres ante los ojos de él ¿porque él la mira no disminuida, ¿cómo la juzga el resto? ¿Por qué ella logra verse completa en él? ¿Por ambas cosas y otras que el verdadero amor provoca? 
Que el pecho se engrandezca es entonces una reacción física, pero está conectada indisolublemente con un sentir legítimo. Implica al cuerpo y al deseo y a Dios, pues viene del amor, de la fe en el amor, y al amor vuelve.

Esto que ella nos dice, como expresión, no deja de estar exenta de erotismo, pero ubica y legitima al mismo en lo que es: un deseo visible que se muestra en la carne, en el cuerpo, pero tiene su origen en algo más profundo.

Sugiere ella -y así enseña- que es el amor el que hace crecer todo, el que dispone a punto nuestros cuerpos para amar. Denuncia en la belleza de esta frase que es el amor y no el lucro el que erige parámetros de idoneidad. Su cuerpo visto como menos desde la mirada superficial y lucrativa, desde estos otros ojos no carece de nada, es tal cual debe ser, se encuentra listo y dispuesto, es ideal.

Este verso 10 trae, sin lugar a duda, un posicionamiento contestatario. Es una declaración socio teológica y política ${ }^{4}$. Lo personal es político, aprendimos con las feministas. ¡La mujer de Cantares, la que cuenta, ya lo mostraba desde su canto!

Este verso contiene una ruptura con esquemas opresores donde las hermanitas son vistas solamente como fuente de ingreso y tienen sólo valor de uso: producir y reproducirse, nada más. Ella se opone a este sistema de esclavitud, a esta práctica culturalmente legitimada de sexo sólo para beneficio de otros, a esta cultura de trata y trato, sexual transaccional.

En este verso alza la voz la mujer-novia-hermana desafiando a un sistema que se empeña en juzgarla por fragmentos, mirarla sólo superficialmente, y menguarla en su libertad. Este sistema se equivoca, la mira mal a ella porque la rompe y la fragmenta en su ser de una manera injusta, utilitaria. Se equivoca porque no sabe apreciar holísticamente lo que significa ser mujer ni lo que significa amar.

Su respuesta descolocada cuestiona el lugar de ellos (los hermanos, la familia, la tradición), mueve sus argumentos, los disloca y saca de sitio de tal forma que de pronto sentimos que estas voces iya no tienen lugar! Es ella la que resitúa todo cuando dice las cosas como son, como las ve, como han de ser... Es ella...

\footnotetext{
${ }^{4}$ Anne-Marie Pelletier alude a una lectura de tipo política, pero más metafórica: “¿quiénes son los que hablan a partir del v. 8? ¿Y quién es esa hermana pequeñita? Una solución es dar aquí una especie de vuelta hacia atrás: los «hijos de la madre» de 1,6 se preocupan de la suerte y del porvenir de la Sulamita, su hermana todavía pequeña. Esta les replicaría que no tiene ya necesidad de sus cuidados. Pero la metáfora de la ciudad es demasiado insistente para que podamos dejarla en el olvido. De ahí la idea de que estos versículos constituirían una relectura política del texto, en un tiempo en que se daría la tentación de olvidar que Jerusalén, figura de Sion, recibe su protección de Dios y no de las almenas de plata o de las planchas de cedro que sus protectores se empeñan en oponer a sus enemigos" (Pelletier, 1995).
} 


\section{Ella, la que cuenta}

Cantares es un libro de amor y lucha, de amor en existencia y resistencia. Como resume Schöekel: "El amor de este libro bíblico todavía tiene resquicios de temor: raposas que destrozan, sorpresas nocturnas, llamar en vano, buscar sin encontrar..." (1969, p. 19).

Todo esto se condensa en la tensión que exponen los versos aquí vistos. Autores como Lurruzaga afirman que si entendemos el concepto de «trato» sobre la hermanita como aquel que entra en juego en la adquisición de la esposa para el contrato matrimonial, se podría pensar que en todo este fragmento están hablando sólo los hermanos carnales de la kalāh, pero que no podemos olvidar que su presencia dentro de Cantares reviste una función también simbólica que tiene que ver con concretar las dificultades que esta - mujer joven con sentimientos y deseos despiertos- sufre por parte de los suyos $(1,6)$ (Luzarraga, 2005) y, como hemos visto, esto contrastaría también con lo que muestra ese plural en el verso 8,9 .

Entre las tantas cosas que parece nos quiere decir- y provocar a hablar- el texto, está insertado sin lugar a duda el tema de la sexualidad. Una de las propuestas de lectura con los lentes de género a propósito de este libro, toca lo concerniente al mito represivo del cual habla Michel Foucault. Mito que por demás tiene presencia en las modernas discusiones sobre sexualidad y sobre el cual Foucault y otros autores básicamente han señalado que se trata de ver cómo los discursos usados para reprimir la sexualidad de hecho han terminado conformando, nombrando e incluso instigando las verdaderas prácticas y desarrollo de las identidades sexuales que quisieron suprimir (Carr, 2000).

De modo que leer Cantares y estos versos desde esta óptica foucaultiana quizás tenga algo importante que decirnos sobre la sobrevivencia de prácticas casamenteras con visos de contrato en nuestros días dentro de los ambientes religiosos cristianos y las sociedades culturalmente conformadas por esta cosmovisión como tal.

¿Quiénes son hoy en día los hermanos, las familias que intentan obtener o dar una kalāh? ¿Quiénes los legitiman con derecho sobre el cuerpo y la vida de alguna âhôt, hermana, mujer joven dentro de los espacios de nuestras prácticas de fe y nuestras sociedades en general?

Con los versos del 8 al 10, estamos en un contexto en que el casamiento era un negocio, un acto de compra y venta. Un ambiente donde cada mujer tenía su precio y una vez comprometida pasaba del dominio del padre y hermanos al del marido. Pero ¿realmente ya han dejado de existir estas concepciones sobre el cuerpo, el amor y la sexualidad?

El Cantar de los Cantares consigna estas negociaciones como despreciables. Y, como apreciaba Milton Schwantes, no es casualidad que estos versos sean palabra de mujer. Son versos de mucha pasión y mucha lucha. Palabras que se oponen frontalmente al sistema de esclavitud matrimonial (Pardo, 2004). 
Aún hoy resulta urgente rescatar la palabra inspirada de esta denuncia que el pasaje hace, entendiendo que implica para posicionarnos también desde la fe liberadora en nuestro mundo actual de trata de mujeres, muchas veces revestida de tratos y contratos donde se tergiversa la imagen del amor legitimando el de la casa (la tradición, el control de los hermanos) por el de los manzanos (el amor creación de Dios, dado por Dios en su libertad plena del acto de crear, y vivido también en el espacio libre donde habita.

Ella, la que cuenta en Cantares, nos ayuda a colocarnos para observar la realidad desde otro sitio, desde el cuerpo. Su palabra es denuncia amorosa. Como señalan otros comentarios no es extraño que su nombre sea Sulamita: "la pacífica", "la plena" o "la completa" (Varios, 1995)

La mujer construida en el Cantar de los Cantares es en mucho el personaje más poderoso y fuera de serie de la Biblia. Ella impreca a Dios con la misma pasión con que le desea. El libro de Cantares viene a decir también algo importante sobre la relación de "jerarquía humano - divina" a través de este carácter que es ella (Carr, 2000 p. 246) y esto debe impactar nuestras prácticas eclesiales, familiares y nuestra cosmovisión patriarcal utilitarista de forma diametral.

La mujer de Cantares 8,8-10 y de todo este libro no quiere ni trata ni contrato, sino trato libre con Dios, pacto de Amor allí en la libertad de los manzanos. Denuncia el maltrato que implica ser vista todo el tiempo como menos.

Reclama para sí- para su mundo- buen trato para un buen vivir más pleno entre mujeres y hombres, en la familia, y en la sociedad. El deseo de vivir, sentir y constituirse desde una Paz que es no violencia, que es equidad, que es goce de los cuerpos que por amor maduran y se entregan. Que más allá de reglas lucrativas y estereotipos en función del lucro, es completitud ante los ojos del que sí nos ama.

Los cuerpos cambian, y esa mujer lo sabe. Por eso cambia el modo en que su cuerpo se debe mirar. Se declara con fuerzas para hacerlo ante quienes cuestionan si ella no puede, si ella es débil. Se declara madura para hacerlo ante quienes cuestionan su capacidad de estar bien preparada, lista o a tiempo para relacionarse como mujer, adultamente y para amar.

Esta mujer no sólo dice, contradice.

No calla, ni se deja así acallar.

Es ella la que cuenta y jasí cuenta! No dándose a la vez por descontada.

Y de esta forma impele a ser siempre nosotras las que contemos; a contar con nosotras desde los cuerpos únicos que somos, a que cuenten con todas iy a cantar! 


\section{Referencias}

CARR, D. Gender and the shaping of desire in the Song of Songs and its interpretation. En: Journal of Biblical Literature, Vol. 119(2), pp. 233248, 2000.

CROATTO, S. Cantar de los Cantares. En: Pastoral Popular No. 249, octubre-noviembre 1995, pp. 22-23, Santiago: Centro Ecuménico Diego de Medellín, 1995.

EATON, M. A., \& Carr, G. L. Eclesiastés e Cantares. Sao Paulo: Vida Nova, 1989.

LACOCQUE, A. Romance she wrote. A hermeneutical essay on Songs of Songs. Pennsylvania: Trinity Press International, 1998.

LUZARRAGA, J. Cantar de los Cantares. Sendas del Amor. Navarra: Verbo Divino, 2005.

PARDO, D. R. Memorias del IV Taller Nacional de Animadores y Animadoras de Lectura Popular de la Biblia con Milton Schwantes. Habana: Red Bíblica Cubana / CECIC. 2004.

PELLETIER, A.-M. El Cantar de los Cantares. Estela (Navarra): Editorial Verbo Divino, 1995.

SCHÖEKEL, L. A. El Cantar de los Cantares. Madrid: Ediciones Cristiandad, 1969.

VARIOS, A. Proverbios, Eclesiastés y Cantares. El Paso (Texas): Editorial Mundo Hispano, 1995. 